\title{
Bovine lactoferrin ingestion protects against inflammation via IL-11 induction in the small intestine of mice with hepatitis
}

\author{
Tetsuya Kuhara*, Azusa Tanaka, Koji Yamauchi and Keiji Iwatsuki \\ Food Science and Technology Institute, Morinaga Milk Industry Company Limited, 5-1-83 Higashihara, Zama, \\ Kanagawa 228-8583, Japan
}

(Submitted 21 February 2013 - Final revision received 22 November 2013 - Accepted 9 December 2013 - First published online 28 January 2014)

\begin{abstract}
Accumulating evidence suggests that orally ingested lactoferrin protects against inflammation. To assess the efficacy of orally administered bovine lactoferrin (bLF) against hepatitis and to identify the underlying mechanism, in the present study, we used four mouse models of hepatitis induced by D-galactosamine (GalN), carbon tetrachloride $\left(\mathrm{CCl}_{4}\right)$, GalN plus lipopolysaccharide (LPS) and zymosan plus LPS. Intraperitoneal (i.p.) injection of GalN $(500 \mathrm{mg} / \mathrm{kg}$ body weight) in mice treated with bovine serum albumin (BSA) for $14 \mathrm{~d}$ significantly increased serum aspartate aminotransferase (AST) concentrations compared with the untreated mice. However, orally administered bLF reduced AST concentrations compared with BSA treatment. In mice that received a single injection $(0.4 \mathrm{ml} / \mathrm{kg})$ and twice-weekly injections $(0.08 \mathrm{ml} / \mathrm{kg})$ of $\mathrm{CCl}_{4}$ for 24 weeks and pretreated with bLF for $14 \mathrm{~d}$ and 24 weeks, respectively, significantly suppressed alanine aminotransferase and AST concentrations were observed compared with the BSA-treated control. Oral administration of bLF for $14 \mathrm{~d}$ before i.p. injection of LPS $(5 \mathrm{mg} / \mathrm{kg})$ plus GalN $(1 \mathrm{~g} / \mathrm{kg})$ significantly improved the survival rate. In mice that received intravenous injection of zymosan $(25 \mathrm{mg} / \mathrm{kg})$ and LPS $(15 \mu \mathrm{g} / \mathrm{kg})$ at $7 \mathrm{~d}$ intervals, bLF reduced the elevation of AST concentrations and enhanced the production of IL-11 and bone morphogenetic protein 2 in the small intestine compared with the BSA-treated control. To evaluate the effects of IL-11, we used IL-11 receptor $\alpha$-null mice treated with GalN, $\mathrm{CCl}_{4}$ and zymosan plus LPS. In this group, the activity of bLF was not significantly different from that of BSA. These data indicate that orally ingested bLF enhances the expression of IL-11 in the small intestine and up-regulates protective activity in mice with hepatitis.
\end{abstract}

\section{Key words: IL-11: Bone morphogenetic protein 2: Hepatitis}

Orally ingested bovine lactoferrin (bLF) has been shown to provide a wide range of benefits in various animal models with inflamed and damaged tissues, such as the large intestine $^{(1)}$, liver ${ }^{(2)}$, oesophagus and lung ${ }^{(3,4)}$, oocytes ${ }^{(5)}$ and bone $^{(6)}$. Clinical use of bLF has also produced several promising outcomes, such as the suppression of colorectal $\operatorname{adenomas}^{(7)}$, the inhibition of hepatic inflammation in chronic hepatitis C patients ${ }^{(8)}$ and the prevention of sepsis in very lowbirth-weight neonates ${ }^{(9)}$. Lactoferrin has physical and chemical properties that protect against oxidative damage ${ }^{(10)}$ and suppress inflammatory cytokine production by interfering with the NF- $\mathrm{B}$ signalling pathway ${ }^{(11)}$. Furthermore, lactoferrin specifically binds to the hepatitis $\mathrm{C}$ virus (HCV), preventing HCV infection ${ }^{(12)}$. However, it has been reported that the pathway and mode of administration of bLF and its manufacturing process influence the physiological functions of $\mathrm{bLF}^{(13)}$. Despite all clinical uses of bLF being oral, most primary studies on the anti-inflammatory effect of bLF have been conducted using other routes of administration ${ }^{(14)}$. In the present study, we first ascertained the anti-inflammatory activity of orally administered bLF using several mouse models of hepatitis. The underlying mechanisms in hepatitis induced by D-galactosamine (GalN), carbon tetrachloride $\left(\mathrm{CCl}_{4}\right)$ and lipopolysaccharide (LPS) plus zymosan involve the cessation of macromolecular biosynthesis in hepatocytes ${ }^{(15)}$, the accumulation of lipid peroxidation and intracellular $\mathrm{Ca}$ ions by trichloromethyl radicals ${ }^{(16)}$ and the production of pro-inflammatory cytokines from activated Kupffer cells ${ }^{(17)}$, respectively. We hypothesised that these various mouse models would be useful to determine the most effective properties and mechanisms of orally administered bLF in hepatitis.

Given that only barely detectable amounts of bLF and its large fragments are absorbed by the intestines ${ }^{(18)}$, it has been assumed that orally ingested bLF cannot exert a

\footnotetext{
Abbreviations: ALT, alanine aminotransferase; AST, aspartate aminotransferase; BMP2, bone morphogenetic protein 2; bLF, bovine lactoferrin; BSA, bovine serum albumin; $\mathrm{CCl}_{4}$, carbon tetrachloride; GalN, D-galactosamine; HCV, hepatitis C virus; i.p., intraperitoneal; i.v., intravenous; IL-11R $\alpha$, IL-11 receptor $\alpha$; LPS, lipopolysaccharide; NK, natural killer.
}

*Corresponding author: T. Kuhara, fax +81 46252 3049, email t_kuhara@morinagamilk.co.jp 
biological response through the direct interaction with target organs, but probably affects digestive tract functions. Previously, we demonstrated that orally ingested bLF enhances IL-18 production in the intestinal epithelium and type I interferon production in Peyer's patches, enhancing peripheral natural killer (NK) cell activity in mice ${ }^{(19)}$ and inhibiting tumour metastasis ${ }^{(4)}$. Our previous study demonstrating the immunomodulatory activity of orally ingested bLF was conducted under inflamed conditions ${ }^{(19)}$, because only minor changes in physiological function can be observed under normal conditions due to oral bLF administration. In rats with colitis induced by 2,4,6-trinitrobenzene sulfonic acid, oral bLF administration has been shown to reduce inflammation by correcting the cytokine imbalance ${ }^{(1)}$; however, inflammation of the intestine made it difficult to analyse the activity of bLF in the intestine. Therefore, in the present study, we analysed the mechanism underlying the anti-inflammatory activity of bLF using a mouse model of hepatitis induced by intravenous (i.v.) injection of zymosan plus LPS to minimise the direct effects of the agent on the intestine ${ }^{(17)}$.

Previously, we demonstrated that bLF passes through the epithelium and directly stimulates IL-11 production in human myofibroblasts, and that IL-11 produced by myofibroblasts exerts protective activity towards epithelial cells ${ }^{(20)}$. IL-11, a pleiotropic cytokine, has a variety of haematopoietic and non-haematopoietic activities ${ }^{(21)}$. The i.v. injection of recombinant human IL-11 prevents $\mathrm{CCl}_{4}$-induced hepatotoxicity $^{(22)}$. IL-11 suppresses the production of inflammatory mediators such as TNF- $\alpha$, IL- $1 \beta$ and NO in activated macrophages via the inhibition of $N F-\kappa B^{(23)}$. Using the zymosan plus LPS-induced hepatitis model, we investigated the effects of orally administered bLF on the expression of inflammatory and anti-inflammatory factors in the small intestine, including IL-11. Furthermore, to clarify the role of IL-11 in the anti-hepatitis activity of bLF, we used IL-11 receptor $\alpha$ (IL-11R $\alpha$ )-deficient mice. It has been demonstrated that in the absence of $\mathrm{IL}-11 \mathrm{R} \alpha$, bone remodelling is impaired through the suppression of osteoblast differentiation ${ }^{(24)}$, and females are infertile due to abnormal development of the placenta ${ }^{(25)}$, due to the loss of IL-11 bioactivity.

\section{Experimental methods}

\section{Mouse models of hepatitis}

All animal studies were approved by the Committee for Animal Care and Oversight of Morinaga Milk Industry in accordance with its guidelines for the care and use of laboratory animals. We used four mouse models of hepatitis induced by GalN, $\mathrm{CCl}_{4}$, GalN plus LPS and zymosan plus LPS, respectively, to examine the anti-hepatitis activity of orally administered bLF. Mice were housed under constant conditions $\left(21-25^{\circ} \mathrm{C}\right.$; humidity, 40-60\%; $12 \mathrm{~h}$ light $-12 \mathrm{~h}$ dark cycle), fed a non-purified diet (Labo MR Stock; Nihon Nosan Kogyo) containing $18.7 \%$ protein, $4.1 \%$ fat, $5.7 \%$ fibre, $6.7 \%$ mineral mixtures and $0.2 \%$ vitamin mixture, and allowed free access to tap water.
Expt 1 involved GalN-induced hepatitis mouse model. In Expt 1A, male CD1 mice (7-8 weeks old; Charles River) were intraperitoneally (i.p.) injected with GalN (Wako Pure Chemical Industries) at a dose of $500 \mathrm{mg} / \mathrm{kg}$ body weight. Mice were then orally administered bLF (Morinaga Milk Industry) at doses of 30,100 and $300 \mathrm{mg} / \mathrm{kg}$ body weight as a suspension in water at a dose of $10 \mathrm{ml} / \mathrm{kg}$ for $14 \mathrm{~d}$ via a gastric tube (bLF-treated group). Bovine serum albumin (BSA, $300 \mathrm{mg} / \mathrm{kg}$ body weight; Sigma-Aldrich) was administered to the BSA-treated control group. On day 14, mice were administered a second i.p. injection of GalN at the same dose. At $18 \mathrm{~h}$ later, mice were anaesthetised using diethyl ether, their blood was harvested and their serum alanine aminotransferase (ALT) and aspartate aminotransferase (AST) concentrations were measured using a colorimetric diagnostic kit (Transaminase CII Test Kit; Wako Pure Chemical Industries). To evaluate the specificity of bLF (Expt 1B), other milk whey proteins ( $\alpha$-lactalbumin, $\beta$-lactoglobulin (Sigma-Aldrich) and BSA) were compared with bLF in the above model. These experiments were repeated twice with eight or nine mice per group. The untreated controls receiving no i.p. injections or oral administrations were also sampled during the experiment.

Expt 2, the $\mathrm{CCl}_{4}$-induced liver injury mouse model, included both acute (Expt 2A) and chronic (Expt 2B) treatments. In Expt 2A, male CD1 mice were orally pre-administered bLF or BSA daily at a dose of $300 \mathrm{mg} / \mathrm{kg}$ body weight for $14 \mathrm{~d}$. On day $14,0.4 \mathrm{ml} / \mathrm{kg}$ body weight of $\mathrm{CCl}_{4}$ (Kanto Chemical) dissolved in olive oil were injected i.p. at a concentration of $20 \%$. After $18 \mathrm{~h}$, blood samples were collected under anaesthesia. The treated group included ten mice and the untreated group comprised six mice. In Expt 2B, chronic liver injury was induced by i.p. injection of $\mathrm{CCl}_{4}$ for 24 weeks. Mice were administered bLF or BSA once daily. On day 5 and then twice weekly, $0.08 \mathrm{ml} / \mathrm{kg}$ body weight of $\mathrm{CCl}_{4}$ dissolved in olive oil were injected i.p. at a concentration of $5 \%$. Mice were killed under anaesthesia at $72 \mathrm{~h}$ after the final injection of $\mathrm{CCl}_{4}$, and blood and liver samples were collected. After fixation in $20 \%$ neutral-buffered formalin (Sakura Finetek), the number and sizes of fibrotic nodules on the surface of the entire liver were macroscopically measured. In the chronic liver injury experiment, serum IL- 6 and TNF- $\alpha$ concentrations were also measured using an ELISA kit (DuoSet ELISA Development System; R\&D Systems). The bLF-treated group included twelve mice, the BSA-treated group eleven and the untreated group six.

Expt 3 was a LPS plus GalN-induced lethality mouse model. GalN was used to increase the sensitivity of mice to the hepatotoxic effects of endotoxin ${ }^{(15)}$. Male CD1 mice were orally administered bLF or BSA at a dose of $300 \mathrm{mg} / \mathrm{kg}$ body weight for $14 \mathrm{~d}$. On day 14 , mice were administered LPS $(5 \mathrm{mg} / \mathrm{kg}$ body weight, Escherichia coli 0111:B4; SigmaAldrich) and GalN ( $1 \mathrm{~g} / \mathrm{kg}$ body weight) i.p. Survival of mice over the following 12, 24, 36 and $72 \mathrm{~h}$ was recorded. This experiment was repeated twice, with twenty-four mice in the bLF-treated group and twenty-two mice in the BSA group.

Expt 4 was a zymosan plus LPS-induced hepatitis mouse model. In Expt 4A, male BALB/c mice (7-8 weeks old; Charles River) were injected with zymosan (Sigma-Aldrich) into the 
tail vein at a dose of $25 \mathrm{mg} / \mathrm{kg}$ body weight on day 0 . BSA or bLF was orally administered on days 1-7 at a dose of $300 \mathrm{mg} / \mathrm{kg}$ body weight once daily. At $3 \mathrm{~h}$ after the final oral administration, $15 \mu \mathrm{g} / \mathrm{kg}$ body weight of LPS was injected intravenously and blood was harvested $18 \mathrm{~h}$ later. This experiment was repeated twice, with twelve mice in each treatment group and six in the untreated group.

\section{Effects of bovine lactoferrin on small-intestinal tissue (Expt 4B)}

Direct effects of bLF on small-intestinal tissue under inflammatory conditions were determined using the i.v. zymosan plus LPS-induced hepatitis model, as described for Expt 4. On days 1,3 and 6 , and $18 \mathrm{~h}$ after LPS injection on day 8 , a mucosal tissue sample excised from the middle section of the small intestine and a portion of the liver were frozen immediately and held at $-80^{\circ} \mathrm{C}$ until further analysis. Several anti-inflammatory factors, inflammatory factors and some related factors were analysed using real-time RT-PCR, as described previously ${ }^{(20)}$. Based on the results from the real-time RT-PCR analysis, IL-11 and bone morphogenetic protein 2 (BMP2) production in the mucosal tissue of the small intestine were analysed by immunoblotting, as described previously ${ }^{(20)}$. Chemiluminescent signals were detected using ECL Plus Western blotting detection reagents and film (GE Healthcare) and quantified using the imaging software cellSens (Olympus). Signal intensity was normalised to that of $\beta$-actin. This experiment was repeated three times, with six mice at each time point.

\section{IL-11 receptor $\alpha$-null mice (Expt 5)}

Fertilised ova targeted at the IL-11 R $\alpha$ locus ${ }^{(26)}$ were obtained from The Jackson Laboratory and IL-11R $\alpha$-null mice were then generated and obtained from Charles River. Heterozygous offspring were inbred to yield wild-type and IL- 11 R $\alpha$-null mice. Mouse genotyping was performed by Southern blot analysis as described previously ${ }^{(26)}$. First, male IL-11R $\alpha$-null mice and wild-type littermates (8-12 weeks old) were used in a zymosan plus LPS-induced hepatitis experiment to evaluate the effects of endogenous IL-11 (Expt 5A). A portion of each liver and the middle section of the small intestine were fixed in $20 \%$ neutral-buffered formalin. Another portion of the small intestine was used for immunoblot analyses. Sections of paraffin-embedded liver and intestinal tissues were stained with haematoxylin and eosin (Muto Pure Chemicals) for histological analyses. Histological assessment of liver damage was microscopically conducted by an observer blinded to the treatment. Scores of grades $0-4$ were assigned based on fibrosis, swelling cells, disarrangement and hyalinisation. Among the wild-type mice, none was categorised as grade 4 . To measure IL-11 and BMP2 production, sections of intestinal tissue were stained using anti-IL-11 or anti-BMP2 antibody (Bioworld Technology) as the primary antibody, Simple Stain Mouse (anti-rabbit; Nichirei Biosciences) as the secondary antibody and a 3,3'-diaminobenzidine substrate (Nichirei Biosciences) according to the standard immunohistochemistry procedures. The sections were examined using light microscopy at
$200 \times$ magnification without knowledge of the treatment group. The intensity of immunostaining was semi-quantitatively graded from 0 to 3 : grade 0 , no staining; grade 1 , focal or weak staining; grade 2 , diffuse, moderate staining; grade 3, strong staining. This experiment was repeated three times, with nine mice in each of the treatment groups and six in the untreated group. Moreover, to investigate whether the endogenous IL-11 induced by bLF exerted anti-inflammatory activity against other forms of hepatitis, GalN- and acute $\mathrm{CCl}_{4}$-induced hepatitis models were also generated using IL-11R $\alpha$-null mice and wild-type littermates (8-12 weeks old, $n$ 6; two pooled experiments). These experiments were designated as Expt 5B and 5C, respectively.

\section{Statistical analyses}

Data are expressed as means and standard deviations. Statistical analyses were performed using StatView 5.0 software (SAS Institute). For single variables, differences among groups were compared using ANOVA followed by the Tukey-Kramer test (ALT and AST concentrations in Expt 1, 2 and 4; TNF- $\alpha$ and IL-6 concentrations in Expt 2; BMP2 contents in Expt 5A). For two variables, we performed a two-way ANOVA followed by the Tukey-Kramer test and Student's unpaired $t$ test (relative expression of mRNA and IL-11 and BMP2 concentrations in Expt 4; ALT concentrations in Expt 5). Variables with unequal variances were log-transformed. Significant differences in final survival (Expt 3) and the incidence of granulomas (Expt 2B) were determined using the $\chi^{2}$ test. The number of granulomas (Expt 2B) was evaluated using the Mann-Whitney $U$ test. To assess the relationships between the degree of inflammation in the liver and IL-11 and BMP2 expression in the small intestine, Spearman's correlation coefficient was calculated for the histological data (Expt 5A). Differences were considered significant at $P<0 \cdot 05$.

\section{Results}

Oral bovine lactoferrin administration prevents the progression of hepatic failure in all hepatitis mouse models

In Expt 1A, i.p. injection of GalN at 2-week intervals significantly elevated serum AST concentrations in the BSA-treated control group compared with the untreated group $18 \mathrm{~h}$ after the last injection of GalN (Fig. 1(B)). Compared with the BSA control treatment, serum AST concentrations decreased in a dose-dependent manner up to $300 \mathrm{mg} / \mathrm{kg}$ body weight via oral administration of bLF for fourteen successive days. Serum ALT levels were significantly different between the BSA-treated controls and mice administered bLF at the dose of $300 \mathrm{mg} / \mathrm{kg}(P<0 \cdot 05)$. In Expt $1 \mathrm{~B}$, oral administration of bLF inhibited the elevation of AST concentrations compared with the BSA control treatment, but other milk whey proteins did not (Fig. 1(D)).

In Expt 2A, serum ALT and AST concentrations in the BSApre-treated control and bLF-pre-administered groups were significantly higher than that of the untreated control group at 

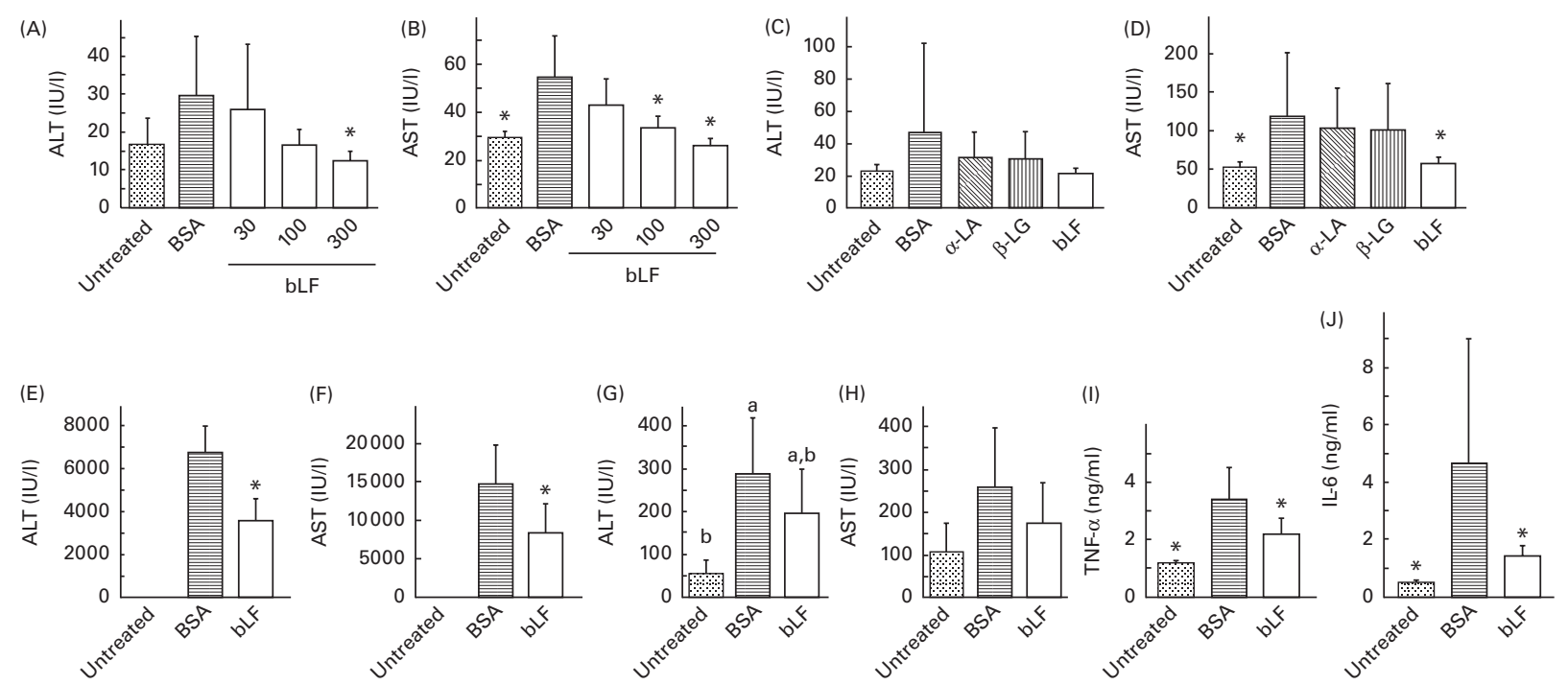

Fig. 1. Effects of oral bovine lactoferrin (bLF) administration on serum alanine aminotransferase (ALT) and aspartate aminotransferase (AST) concentrations in mice with hepatitis induced by intraperitoneal (i.p.) injection of D-galactosamine (GalN) (A-D; Expt 1) and carbon tetrachloride (CCl 4 ) (E-J; Expt 2). In Expt 1, GalN was injected i.p. into mice at an interval of $14 \mathrm{~d}$. bLF was orally administered for $14 \mathrm{~d}$ at a dose of 30,100 or $300 \mathrm{mg} / \mathrm{kg}$ body weight (A, B), or bovine serum albumin (BSA), $\alpha$-lactalbumin ( $\alpha$-LA) or $\beta$-lactoglobulin $(\beta-L G)$, and bLF were administered at a dose of $300 \mathrm{mg} / \mathrm{kg}$ body weight for $14 \mathrm{~d}$. At $18 \mathrm{~h}$ after the second injection of GalN, serum ALT and AST concentrations were determined ( $n 8$ or 9 ; two pooled experiments). In Expt $2 \mathrm{~A}$ (acute hepatitis model), CCl 4 was injected i.p. into mice at a dose of $0.4 \mathrm{ml} / \mathrm{kg}$ after oral administration of bLF and BSA for $14 \mathrm{~d}$. At $18 \mathrm{~h}$ later, serum ALT and AST concentrations were determined ( $n$ 10; untreated mice, $n 6$ ). In Expt $2 \mathrm{~B}$ (chronic hepatitis model), $\mathrm{CCl}_{4}$ was injected i.p. into mice at a dose of $0.08 \mathrm{ml} / \mathrm{kg}$ twice weekly for 24 weeks. bLF and $\mathrm{BSA}$ were orally administered during these periods. At $72 \mathrm{~h}$ after the final injection of $\mathrm{CCl}_{4}$, serum ALT, AST, TNF- $\alpha$ and IL-6 concentrations were determined $(n 11$ or 12 ; untreated mice, $n 6$ ). ALT, AST, and IL-6 values were log-transformed before ANOVA calculations to adjust for unequal variances. In Expt $2 \mathrm{~A}$, among the CCl ${ }_{4}-$ administered groups, the bLF and BSA control groups were compared using an unpaired $t$ test. Values are means, with their standard deviations represented by vertical bars. ${ }^{\mathrm{a}, \mathrm{b}}$ Mean values with unlike letters were significantly different $(P<0.05)$. ${ }^{*}$ Mean value was significantly different from that of the BSA-treated control group $(P<0.05)$.

$18 \mathrm{~h}$ after i.p. injection of $\mathrm{CCl}_{4}(P<0 \cdot 05$; Fig. 1(E) and (F)). However, serum ALT and AST concentrations were significantly lower in the bLF-pre-administered group than in the BSA-pretreated control group $(P<0.05)$. In the chronic hepatitis experiment (Expt 2B), serum ALT concentrations were also elevated in the BSA-treated control group at $72 \mathrm{~h}$ after the final injection of $\mathrm{CCl}_{4} \quad(P<0 \cdot 05$; Fig. $1(G))$. Oral bLF administration for 24 weeks suppressed the increase in serum ALT concentrations to levels that did not significantly differ from that of the untreated control group. Oral administration of bLF also significantly improved serum TNF- $\alpha$ and IL- 6 levels compared with the levels of the BSA-treated control group $(P<0 \cdot 05$, Fig. 1(I) and (J)). Fibrotic nodules were produced on the surface of the liver after i.p. injection of $\mathrm{CCl}_{4}$ for 24 weeks. The incidence of nodules $>5 \mathrm{~mm}$ in diameter was $58.3 \%$ for the BSA-treated control and $16.7 \%$ for the bLF-treated group $(P<0.05)$. The numbers of nodules $<5 \mathrm{~mm}$ in diameter were $5 \cdot 17$ (SD 2.29) and 2.64 (SD 1.96), respectively ( $P<0.05)$.

In Expt 3, i.p. injection of GalN plus LPS following preadministration of BSA for $14 \mathrm{~d}$ induced a high incidence of mortality in mice; $12 \mathrm{~h}$ after i.p. injection, the survival rate was only $18.2 \%$. However, pre-administration of bLF improved the survival rate to $45.8 \%(P<0 \cdot 05)$. Both the survival rates were unchanged throughout the experiment $(72 \mathrm{~h})$.

In Expt 4A, i.v. injection of LPS at $7 \mathrm{~d}$ after zymosan treatment induced a significant elevation of serum ALT and AST concentrations $18 \mathrm{~h}$ after LPS injection in the BSA-treated control group compared with the untreated group $(P<0 \cdot 05$; Fig. 2(A) and (B)). Administration of bLF significantly inhibited the increase in serum AST concentrations compared with the BSA-treated control group $(P<0.05)$, and suppressed the increase in serum ALT levels to levels that did not significantly differ from that of the untreated group.

In Expt 4B, which was designed to avoid inflammation in the intestine, oral administration of bLF enhanced IL-11 and BMP2 expression in the small intestine. In a zymosan plus LPS-induced hepatitis model, profiling of changes in the expression of inflammatory and anti-inflammatory factors in the small intestine revealed a gradual increase in the mRNA expression of $I L-11$ during bLF administration (Table 1). On day 6 , the mRNA expression of $I L-11$ was significantly higher in the bLF-treated group than in the BSA-treated control group $(P<0.05)$. The mRNA expression of $B M P 2$ was also elevated in the bLF-treated group after LPS injection compared with the basal level before LPS injection $(P<0.05)$. Expression of the other factors tested, including $I L-1 \beta, T N F-\alpha$ and transforming growth factor- $\beta$, did not change in the small intestine (data not shown). Thus, neither of the inflammationinducing agents directly influenced small-intestinal tissue in this model. Immunoblot analyses also revealed an increase in IL-11 production in the small intestine following bLF administration after zymosan injection (Fig. 2(C) and (D)). IL-11 levels in the small intestine were higher in the bLFtreated group than in the BSA-treated control group $(P<0.05)$. Oral administration of bLF induced an increase in BMP2 production in the small intestine after i.v. injection of LPS ( $P<0.05$; Fig. $2(\mathrm{E})$ and $(\mathrm{F}))$. In the small intestine, mRNA expression of suppressor of cytokine signal 3 (SOCS3), 
(A)

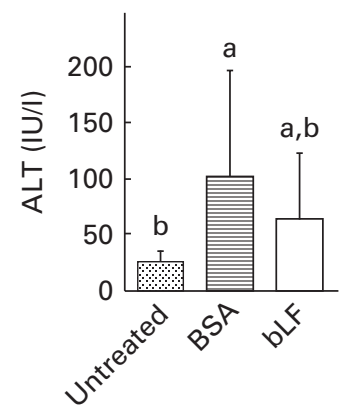

(C)

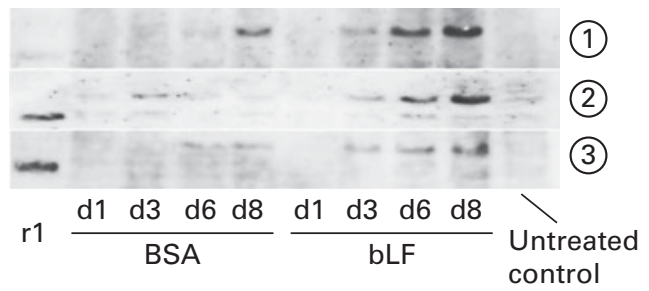

$(\mathrm{E})$
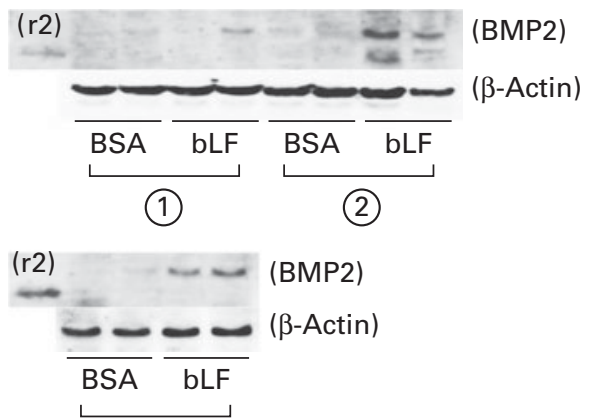

(3)
(B)

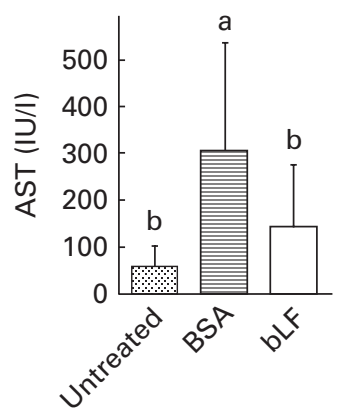

(D)

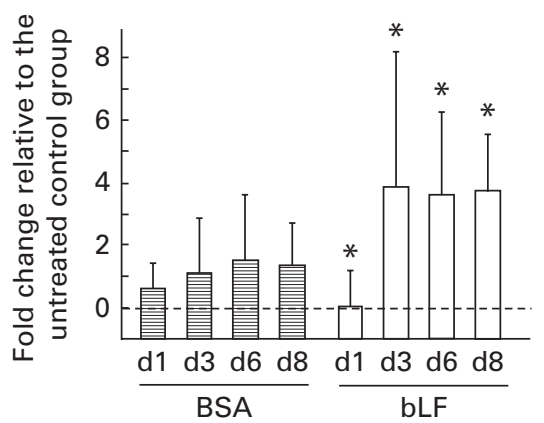

(F)

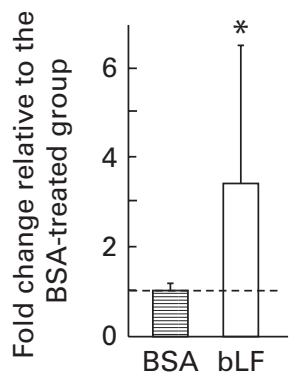

Fig. 2. Effects of oral bovine lactoferrin (bLF) administration on serum alanine aminotransferase (ALT) and aspartate aminotransferase (AST) concentrations, and production of IL-11 and bone morphogenetic protein 2 (BMP2) in the small intestine of mice with zymosan plus lipopolysaccharide (LPS)-induced hepatitis (Expt 4A). Zymosan and LPS were injected intravenously into mice at an interval of $7 \mathrm{~d}$. bLF and bovine serum albumin (BSA) were orally administered for $7 \mathrm{~d}$. At $18 \mathrm{~h}$ after the final injection of LPS, serum ALT (A) and AST (B) concentrations were determined. ALT and AST values were log-transformed before ANOVA calculations to adjust for unequal variances. Values are means ( $n 6$ in the untreated control group and $n 12$ in the zymosan plus LPS group; two pooled experiments), with their standard deviations represented by vertical bars. ${ }^{\mathrm{a}, \mathrm{b}}$ Mean values with unlike letters were significantly different $(P<0.05)$. Samples of intestinal mucosa (Expt 4B) were subjected to immunoblot analyses for IL-11 (C) and BMP2 (E) at days 1, 3, 6 and 8 after injection of zymosan. The immunoblots for IL-11 (C) and BMP2 (E) shown are representative of three separate experiments (ㄱ, (2) and (3)). Signal intensities of IL-11 (D) and BMP2 (F) were normalised to that of $\beta$-actin and are presented as a multiple of the mean of the untreated group ( $n 6$ at each time point; three pooled experiments). (D) Values of IL-11 were analysed for treatment (untreated, BSA-treated and bLF-treated) and time (days 1, 3, 6 and 8) by two-way ANOVA. (F) Values of BMP2 at day 8 were analysed for treatment (BSA-treated and bLF-treated) using one-way ANOVA. Values were log-transformed before ANOVA calculations to adjust for unequal variances. Values are means, with their standard deviations represented by vertical bars. ${ }^{*}$ Mean value was significantly different from that of the BSA-treated control group $(P<0.05)$. d1, d3, d6 and d8, days after administration of zymosan; r1, recombinant IL-11; r2, recombinant BMP2.

a suppressor of cytokine signalling via gp130, was markedly elevated after LPS injection, mirroring IL-11 production. In addition, mRNA expression of a negative regulatory molecule in BMP2 signalling, Smad6, was reduced by bLF, but not BSA, at days 3 and $8(P<0 \cdot 05$; Table 1$)$.

We also examined the mRNA expression of $I L-11, B M P 2$ and the inflammatory cytokines $I L-1 \beta$ and $T N F-\alpha$ in the liver. Expression of $I L-1 \beta$ and $T N F-\alpha$ mRNA gradually increased after injection of zymosan, and LPS treatment strongly enhanced the levels of these mRNA, presumably reflecting inflammation (Table 2). Oral administration of bLF suppressed the expression of $I L-1 \beta$ at days 6 and 8 and the expression of $T N F-\alpha$ at day 6 compared with the BSA-treated control group $(P<0.05)$. After LPS treatment, mRNA expression of $I L-11$ in the BSA-treated control group increased relative to the basal mRNA levels of $I L-11(P<0 \cdot 05)$. In the bLF-treated group, mRNA expression of $I L-11$ was significantly lower $(P<0.05)$ than that in the BSA-treated control group before LPS injection. Unlike $I L-11$, mRNA expression of $B M P 2$ in the liver was not affected in these mice. 
Table 1. Effects of oral administration of bovine lactoferrin (bLF) on small-intestinal mRNA levels of IL-11, bone morphogenetic protein 2 (BMP2), suppressor of cytokine signal 3 (SOCS3) and Smad6 in mice with hepatitis induced by intravenous injection of zymosan plus lipopolysaccharide at days 1, 3, 6 and 8 after administration of zymosan (Expt 4)

(Mean values and standard deviations) $\dagger$

\begin{tabular}{|c|c|c|c|c|c|c|c|c|}
\hline & \multicolumn{2}{|c|}{ Day 1} & \multicolumn{2}{|c|}{ Day 3} & \multicolumn{2}{|c|}{ Day 6} & \multicolumn{2}{|c|}{ Day 8} \\
\hline & Mean & SD & Mean & SD & Mean & SD & Mean & SD \\
\hline \multicolumn{9}{|l|}{$I L-11$} \\
\hline Untreated & $1.0 \ddagger$ & 0.5 & & & & & & \\
\hline BSA & 0.9 & 0.3 & $1 \cdot 3$ & 0.3 & $1 \cdot 1$ & 0.3 & $1 \cdot 1$ & 0.6 \\
\hline bLF & $0.9^{\mathrm{b}}$ & 0.3 & $1 \cdot 4^{\mathrm{a}, \mathrm{b}}$ & 0.2 & $2 \cdot 2^{a *}$ & 1.0 & $1 \cdot 7^{\mathrm{a}, \mathrm{b}}$ & 0.6 \\
\hline \multicolumn{9}{|l|}{ BMP2 } \\
\hline Untreated & $1 \cdot 0$ & 0.5 & & & & & & \\
\hline BSA & 0.6 & 0.2 & $1 \cdot 2$ & 0.5 & 0.9 & 0.3 & 1.4 & 0.8 \\
\hline bLF & $0.8^{\mathrm{b}}$ & 0.2 & $1 \cdot 1^{\mathrm{b}}$ & 0.3 & $1 \cdot 0^{b}$ & 0.3 & $2 \cdot 8^{\mathrm{a}}$ & $1 \cdot 3$ \\
\hline \multicolumn{9}{|l|}{ sOcs3§ } \\
\hline Untreated & 1.0 & 0.4 & & & & & & \\
\hline BSA & $1 \cdot 1^{\mathrm{b}}$ & 0.6 & $1.9^{\mathrm{a}, \mathrm{b}}$ & 0.7 & $1.4^{b}$ & 0.3 & $7 \cdot 7^{\mathrm{a}}$ & 6.0 \\
\hline bLF & $1.0^{\mathrm{b}}$ & 0.2 & $1 \cdot 3^{b}$ & 0.7 & $1 \cdot 0^{\mathrm{b}}$ & 0.4 & $14 \cdot 7^{\mathrm{a}}$ & 8.3 \\
\hline \multicolumn{9}{|l|}{ Smad6 } \\
\hline Untreated & 1.0 & 0.3 & & & & & & \\
\hline BSA & 0.9 & 0.3 & $1 \cdot 1$ & 0.3 & 1.0 & 0.1 & $1 \cdot 1$ & 0.1 \\
\hline bLF & $0.9^{\mathrm{a}}$ & 0.4 & $0.6^{\mathrm{a}, \mathrm{b} *}$ & 0.0 & $0.7^{a, b}$ & 0.3 & $0.3^{\mathrm{b} *}$ & 0.1 \\
\hline \multicolumn{9}{|c|}{$P$ (ANOVA analysis) } \\
\hline & \multicolumn{2}{|c|}{$T$} & \multicolumn{2}{|c|}{$D$} & \multicolumn{2}{|c|}{$T \times D$} & & \\
\hline$I L-11$ & \multicolumn{2}{|c|}{0.008} & \multicolumn{2}{|c|}{0.045} & \multicolumn{2}{|c|}{0.104} & & \\
\hline$B M P 2$ & \multirow{2}{*}{\multicolumn{2}{|c|}{$\begin{array}{l}0.062 \\
0.975\end{array}$}} & \multicolumn{2}{|c|}{$<0.001$} & \multicolumn{2}{|c|}{0.043} & & \\
\hline socs 3 & & & \multirow{2}{*}{\multicolumn{2}{|c|}{$\begin{array}{l}<0.001 \\
<0.001\end{array}$}} & \multirow{2}{*}{\multicolumn{2}{|c|}{$\begin{array}{l}0.079 \\
0.177\end{array}$}} & & \\
\hline Smad6 & \multicolumn{2}{|c|}{0.004} & & & & & & \\
\hline
\end{tabular}

BSA, bovine serum albumin; $T$, treatment; $D$, time.

${ }_{\mathrm{a}, \mathrm{b}}$ Mean values within a row with unlike superscript letters were significantly different $(P<0.05)$.

* Mean value was significantly different from that of the BSA-treated control group $(P<0.05$; unpaired $t$ test).

$\dagger$ Fold of the mean of the untreated group, $n 6$ at each time point (three pooled experiments).

¥ mRNA obtained from the untreated control group were isolated at the same time as the other group or at the

beginning or end of the experiment, as the case may be.

$\S$ SOCS3 values were log-transformed before ANOVA calculations to adjust for unequal variances.

\section{Anti-inflammatory activity of bovine lactoferrin is} abolished in IL-11 receptor $\alpha$-null mice (Expt 5)

IL-11R $\alpha$-null mice and wild-type littermates were used to evaluate the effect of endogenous IL-11. Zymosan plus LPS injected intravenously induced a similar degree of hepatic failure in both wild-type and IL-11R $\alpha$-null mice (Fig. 3(A)). In wild-type mice, oral administration of bLF lowered serum ALT concentrations compared with that in the BSA-treated control group $18 \mathrm{~h}$ after LPS injection $(P<0 \cdot 05)$. However, in IL-11R $\alpha$-null mice, administration of bLF did not suppress the increase in the levels of this indicator.

Immunohistochemical staining revealed the expression of IL-11 in the epithelium and in mesenchymal cells underlying the epithelium. In wild-type mice, the intensity of staining for IL-11 in the bLF-treated group (Fig. 3(D)) was greater than that in the BSA-treated control group $18 \mathrm{~h}$ after LPS injection (Fig. 3(E)), and similar results were obtained for IL-11R $\alpha$-null mice (Fig. 3(F)). The expression of BMP2 was mainly detected in the epithelium. For wild-type mice, administration of bLF, but not BSA, increased the intensity of BMP2 staining (Fig. 3(G) and (H)). BMP2 expression was also not observed in either treatment of IL-11R $\alpha$-null mice (Fig. 3(I)). Immunoblot analyses revealed that after i.v. injection of LPS, the production of intestinal BMP2 induced by bLF administration was suppressed in IL-11R $\alpha$-null mice $(P<0 \cdot 05$; Fig. 3(B) and (C)). Histochemical analyses showed no inflammation in the small intestine (data not shown), in accordance with our experimental design.

The anti-inflammatory activity of orally administered bLF was also examined in the GalN- and acute $\mathrm{CCl}_{4}$-induced hepatitis models using IL-11R $\alpha$-null mice. Similar to that in CD1 mice in Expt 1, oral administration of bLF for $14 \mathrm{~d}$ suppressed the increase in serum ALT levels in the B6-background wildtype mice $(P=0.066)$; however, in IL-11R $\alpha$-null mice, bLF administration did not reduce serum ALT levels (Expt 5B; Fig. 3(J)). Furthermore, pre-treatment with bLF for $14 \mathrm{~d}$ significantly inhibited the $\mathrm{CCl}_{4}$-induced increase in serum ALT levels in wild-type mice $(P<0.05)$, although this treatment was not efficacious in IL-11R $\alpha$-null mice in Expt 5C (Fig. 3(K)).

Finally, correlations between the hepatic inflammation score and the expression of IL-11 and BMP2 in the small intestine were calculated based on the histochemical results (Fig. 4). The inflammation scores generally paralleled serum ALT and AST levels. In wild-type mice, the expression score for IL-11 in the bLF-treated group was negatively correlated with the hepatic inflammation score $(P<0 \cdot 05$; Fig. $4(\mathrm{~A}))$; however, no 
Table 2. Effects of oral administration of bovine lactoferrin (bLF) on liver mRNA levels of $I L-1 \beta$, $T N F-\alpha, I L-11$ and bone morphogenetic protein 2 (BMP2) in mice with hepatitis induced by intravenous injection of zymosan plus lipopolysaccharide at days 1, 3, 6 and 8 after administration of zymosan (Expt 4)

(Mean values and standard deviations) $\dagger$

\begin{tabular}{|c|c|c|c|c|c|c|c|c|}
\hline & \multicolumn{2}{|c|}{ Day 1} & \multicolumn{2}{|c|}{ Day 3} & \multicolumn{2}{|c|}{ Day 6} & \multicolumn{2}{|c|}{ Day 8} \\
\hline & Mean & SD & Mean & $\mathrm{SD}$ & Mean & SD & Mean & SD \\
\hline \multicolumn{9}{|l|}{$I L-1 \beta \ddagger$} \\
\hline Untreated§ & 1.0 & 0.6 & & & & & & \\
\hline BSA & $0.6^{\mathrm{d}}$ & 0.1 & $3 \cdot 5^{\mathrm{c}}$ & $1 \cdot 8$ & $7 \cdot 6^{\mathrm{b}}$ & $2 \cdot 2$ & $67 \cdot 8^{a}$ & $10 \cdot 8$ \\
\hline bLF & $0.4^{\mathrm{C}}$ & 0.1 & $1 \cdot 6^{\mathrm{b}, \mathrm{c}}$ & 1.0 & $2 \cdot 5^{\mathrm{b} *}$ & $2 \cdot 3$ & $47 \cdot 2^{a \star}$ & $10 \cdot 0$ \\
\hline \multicolumn{9}{|l|}{$T N F-\alpha \ddagger$} \\
\hline Untreated & 1.0 & $1 \cdot 1$ & & & & & & \\
\hline BSA & $1.0^{\mathrm{C}}$ & 0.3 & $10 \cdot 3^{b, c}$ & $9 \cdot 2$ & $34.1^{\mathrm{b}}$ & $27 \cdot 8$ & $630.0^{\mathrm{a}}$ & 398.0 \\
\hline bLF & $1.0^{\mathrm{b}}$ & 0.5 & $10 \cdot 0^{\mathrm{b}}$ & 8.7 & $8 \cdot 5^{\mathrm{b} *}$ & 11.8 & $403 \cdot 0^{\mathrm{a}}$ & 144.0 \\
\hline \multicolumn{9}{|l|}{ IL-11‡ } \\
\hline Untreated & 1.0 & 0.3 & & & & & & \\
\hline BSA & $0.8^{\mathrm{b}}$ & 0.4 & $1.8^{\mathrm{b}}$ & 0.7 & $4 \cdot 2^{b}$ & 1.6 & $84 \cdot 1^{\mathrm{a}}$ & 67.8 \\
\hline bLF & $0.9^{b}$ & 0.2 & $1.3^{\mathrm{b}}$ & 0.6 & $1.5^{\mathrm{b} *}$ & 1.4 & $18 \cdot 9^{a}$ & 26.8 \\
\hline \multicolumn{9}{|l|}{ BMP2 } \\
\hline Untreated & 1.0 & 0.5 & & & & & & \\
\hline BSA & $1 \cdot 1$ & 0.4 & 1.6 & 0.2 & 1.4 & 0.5 & 1.6 & 0.6 \\
\hline bLF & 1.4 & 0.1 & $1 \cdot 3$ & 0.3 & $1 \cdot 3$ & 0.5 & $1 \cdot 1$ & 0.5 \\
\hline \multicolumn{9}{|c|}{$P$ (ANOVA analysis) } \\
\hline & \multicolumn{2}{|c|}{$T$} & \multicolumn{2}{|c|}{$D$} & \multicolumn{2}{|c|}{$T \times D$} & & \\
\hline$I L-1 \beta$ & \multicolumn{2}{|c|}{$<0.001$} & \multicolumn{2}{|c|}{$<0.001$} & \multicolumn{2}{|c|}{0.102} & & \\
\hline$T N F-\alpha$ & \multirow{2}{*}{\multicolumn{2}{|c|}{$\begin{array}{l}0.382 \\
0.014\end{array}$}} & \multirow{2}{*}{\multicolumn{2}{|c|}{$\begin{array}{r}0.001 \\
-0.001\end{array}$}} & \multicolumn{2}{|c|}{$0 \cdot 101$} & & \\
\hline $\mid L-11$ & & & \multirow{2}{*}{\multicolumn{2}{|c|}{0.680}} & \multirow{2}{*}{\multicolumn{2}{|c|}{$\begin{array}{l}0.063 \\
0.331\end{array}$}} & & \\
\hline BMP2 & \multicolumn{2}{|c|}{0.342} & & & & & & \\
\hline
\end{tabular}

BSA, bovine serum albumin; $T$, treatment; $D$, time.

$\mathrm{a}, \mathrm{b}, \mathrm{c}, \mathrm{d}$ Mean values within a row with unlike superscript letters were significantly different $(P<0.05)$.

* Mean value was significantly different from that of the BSA-treated control group $(P<0.05$; unpaired $t$ test).

$\dagger$ Fold of the mean of the untreated group, $n 6$ at each time point (three pooled experiments).

$\ddagger I L-1 \beta, T N F-\alpha$ and $I L-11$ values were log-transformed before ANOVA calculations to adjust for unequal variances.

$\S$ mRNA obtained from the untreated control group were isolated at the same time as the other group or at the beginning or end of the experiment, as the case may be.

negative correlation was observed with BMP2 expression (Fig. 4(C)). In IL-11R $\alpha$-null mice, there was no correlation between the inflammation score and the expression of IL-11 (Fig. 4(B)) or BMP2 (Fig. 4(D))

\section{Discussion}

In the present study, we demonstrated that oral administration of bLF exerts anti-inflammatory activity in several mouse models of hepatitis designed to correspond to clinical disorders, such as chronic biliary disease, GalN-induced hepatitis ${ }^{(27)}$, hypoplastic liver injury, $\mathrm{CCl}_{4}$-induced hepatitis ${ }^{(16)}$ and hepatitis virus infection, using LPS ${ }^{(15)}$. A few small clinical studies have suggested that bLF ingestion decreases serum ALT and HCV RNA concentrations ${ }^{(8,28)}$; however, a randomised, doubleblind, placebo-controlled, large-scale trial of bLF in patients with chronic hepatitis $\mathrm{C}$ did not demonstrate significant efficacy ${ }^{(29)}$. Furthermore, in a clinical study of ninety patients with chronic hepatitis $\mathrm{C}$, oral administration of bLF inhibited lipid peroxidation and the elevation of serum ALT concentrations, but did not alter serum HCV RNA levels ${ }^{(30)}$. These clinical data imply limited antiviral activity and effective anti-inflammatory activity of bLF in hepatitis patients.
Given the observation that oral bLF administration before the occurrence of inflammation suppressed serum AST levels (Expt 2A) and the mortality rate (Expt 3), and that ingested bLF was not detected in the portal vein ${ }^{(17)}$, we hypothesise that bLF acts as a modulator on an intestinal function and, subsequently, anti-inflammatory and restorative factors are produced and propagated. In the zymosan plus LPS-induced hepatitis model of the present study, we searched for such factors and identified IL-11 and BMP2. In the reported experimental models, IL-11 has exhibited effectiveness in rats with colitis $^{(31)}$ and in mice with hepatitis ${ }^{(32)}$, as with bLF. Some clinical effects of IL-11 treatment are also similar to those of bLF. In patients undergoing chemotherapy, IL-11 prevents gastrointestinal epithelial disintegrity and gut-associated infections $^{(33)}$. bLF supplementation prevents sepsis in neonates ${ }^{(9)}$. In patients with psoriasis, IL-11 reduced cutaneous inflammation $^{(34)}$. Oral administration of bLF improved dermatological inflammatory symptoms in patients with tinea pedis ${ }^{(35)}$. In addition, a clinical study of $\mathrm{HCV}$ patients has suggested that IL-11 has beneficial anti-inflammatory effects $^{(36)}$. In the zymosan plus LPS-induced hepatitis model, we attempted to measure serum IL-11 concentrations in the portal vein following the administration of bLF; however, 


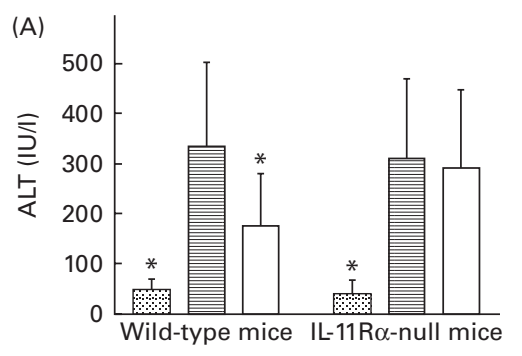

(B)

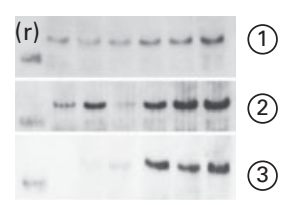

IL-11R $\alpha$ - Wild-type null mice mice
(C)

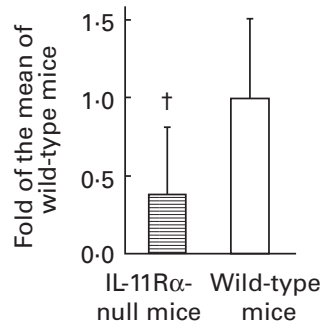

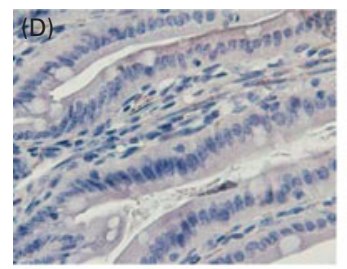
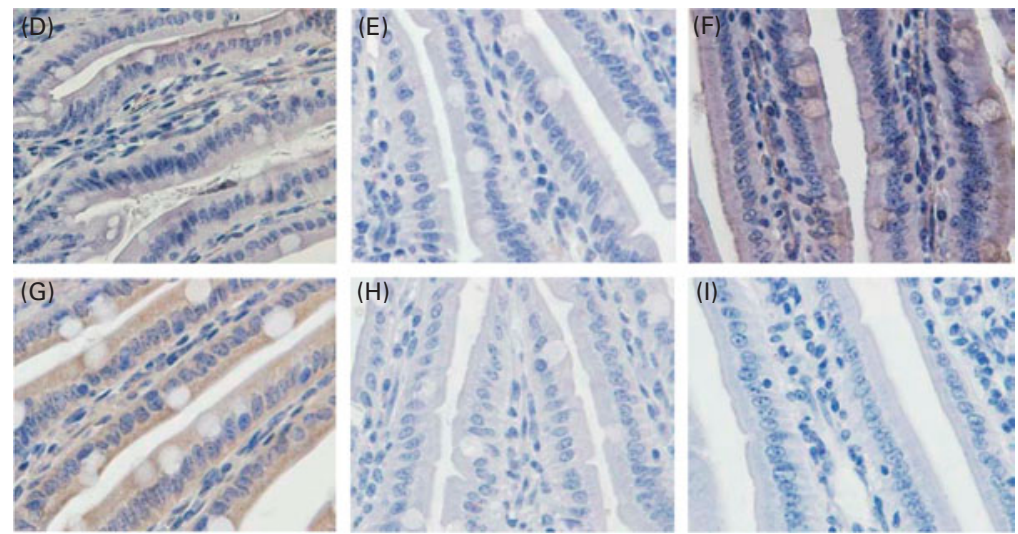

(J)

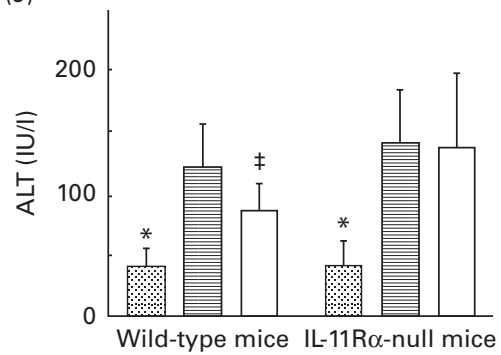

(K)

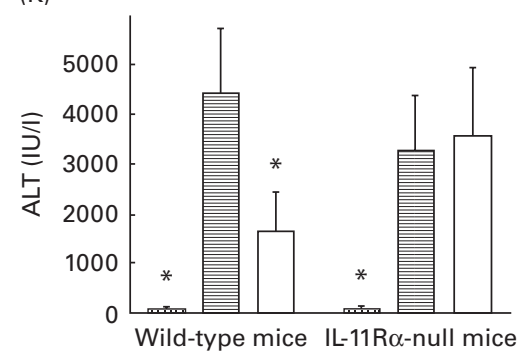

Fig. 3. Comparison of the anti-inflammatory activity of orally administered bovine lactoferrin (bLF) between IL-11 receptor $\alpha$ (IL-11R $\alpha$ )-null mice and wild-type mice (Expt 5). Mouse models of hepatitis induced by D-galactosamine (GaIN), carbon tetrachloride $\left(\mathrm{CCl}_{4}\right)$ and zymosan plus lipopolysaccharide (LPS) were generated using IL-11R $\alpha$-null mice and wild-type littermates. In Expt 5A, the zymosan plus LPS-induced hepatitis mouse model was treated as in Expt 4. Values are means ( $n 6$ in the untreated group and $n 9$ in the zymosan plus LPS-treated group, two pooled experiments), with their standard deviations represented by vertical bars (A). * Mean value was significantly different from that of the BSA-treated control group $(P<0.05)$. Immunohistochemical analyses for IL-11 (D-F) and bone morphogenetic protein 2 (BMP2) $(G-I)$, and representative results for bLF-treated wild-type mice (D, G), BSA-treated wild-type mice (E, H) and bLF-treated IL-11R $\alpha$-null mice $(F, I)$ are shown. BMP2 levels in the intestine of bLF-administered wild-type and IL-11R $\alpha$-null mice were analysed by immunoblotting (B). Signal intensities of BMP2 (C) were normalised to that of $\beta$-actin. Values are multiples of the mean of wild-type mice, with their standard deviations represented by vertical bars. $\dagger$ Mean value was significantly different from that of wild-type mice $(P<0.05$; ANOVA). In Expt 5B, the GalN-induced hepatitis mouse model was treated as in Expt 1 ( $n 6$; two pooled experiments). In Expt $5 \mathrm{C}$, the acute $\mathrm{CCl}_{4}$-induced hepatitis mouse model was treated as in Expt $2 \mathrm{~A}$ ( $n 6$; two pooled experiments). ALT values (A, J, K) were log-transformed before two-way ANOVA calculations to adjust for unequal variances. Values are means, with their standard deviations represented by vertical bars $(\mathrm{J}, \mathrm{K})$. * Mean value was significantly different from that of the BSA-treated control group $(P<0.05)$. $¥$ Mean value was significantly different from that of the BSAtreated control group $(P<0.066)$. (1), (2) and (3), Three separate experiments; r, recombinant BMP2. $\square$, Untreated mice; 目, BSA-treated mice; $\square$, bLF-treated mice.

its concentration was undetectable in many samples. Serum IL-11 concentrations were detected only in a few oral bLF-treated mice, but not in the BSA group (data not shown). However, induction of IL-11 production in the intestine supports the beneficial effect of orally administered bLF, because the anti-inflammatory effect of orally administered bLF completely disappeared in IL-11R $\alpha$-null mice. These observations in IL-11R $\alpha$-impaired mice suggest that bLF activity is mediated by IL- 11 .

In the present study, we also observed that oral administration of bLF significantly increased BMP2 expression. BMP2 performs a variety of functions, including embryonic development, bone morphogenetic differentiation and regulation of systemic Fe balance ${ }^{(37,38)}$. Additionally, it has been suggested that BMP2 regulates bone homeostasis in concert with IL-11 ${ }^{(39)}$, i.e. IL-11 enhances BMP2-Smad1 signalling via formation of the Smad1-STAT3 (signal transducer and activator of transcription 3) complex ${ }^{(40)}$, leading to osteoblastogenesis. BMP2 has been shown to play an important role in the wound-healing response in rats with $\mathrm{CCl}_{4}$-induced hepatitis $^{(16)}$. In the present study, mRNA expression of $I L-11$ in the small intestine was elevated before LPS injection (Table 1), but an increase in the mRNA expression of $B M P 2$ was not noted until after LPS injection. We previously demonstrated that bLF did not directly stimulate the expression of BMP2 in 
(A)

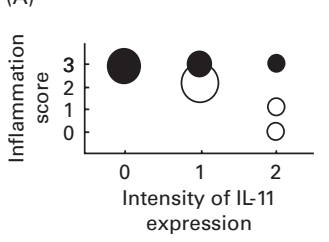

(C)

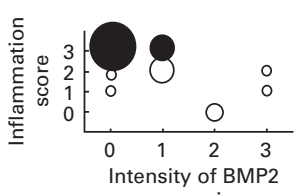

(B)
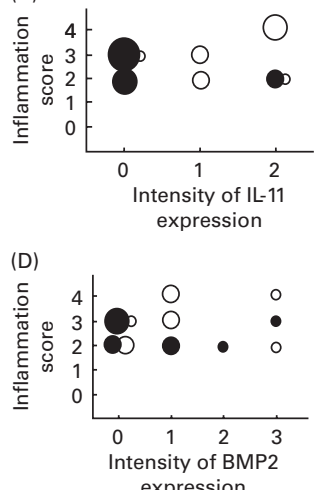

BSA bLF $\underline{n}$

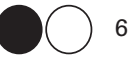

$\bigcirc \bigcirc 5$

- 14

- 3

- 02

- 01
Fig. 4. Correlations between histological scores for liver damage and intestinal IL-11 (A, B) and bone morphogenetic protein 2 (BMP2) (C, D) expression in wild-type $(A, C)$ and IL-11 receptor $\alpha$-null $(B, D)$ mice with zymosan plus lipopolysaccharide-induced hepatitis (Expt 5). The sizes of (control) and $\bigcirc$ (bovine lactoferrin (bLF)-treated) represent the number of mice ( $n$ 9; three pooled experiments). $r$, Spearman's correlation coefficient. (A) $r-0.62$, bLF: $r-0.91(P<0.05)$; (B) $r 0.21$; (C) $r-0.57(P<0.05)$, bLF: $r-0.04$; (D) $r 0.19$.

cultured intestinal epithelial cells, myofibroblasts or monocytes $^{(20)}$. In the present study, bLF-induced enhancement of BMP2 production was reduced in IL-11R $\alpha$-null mice (Fig. 3(B) and (C)). In addition, expression of Smad6, a suppressor of BMP2 signalling, was suppressed by bLF administration (Table 1). Collectively, these results suggest that bLF regulates BMP2 production and activity in the intestinal epithelium via induction of IL-11, as in osteoblastogenesis ${ }^{(39)}$. In the present study, BMP2 expression in the small intestine was not correlated with the anti-inflammatory activity of orally administered bLF (Fig. 4). BMP2 expression in the liver did not increase in mice with hepatitis, suggesting that the anti-inflammatory activity of BMP2 is limited in mouse models.

In clinical trials, bLF ingestion significantly retarded the growth of adenomatous colorectal polyps ${ }^{(7)}$. In the same trials, bLF administration significantly enhanced NK cell activity throughout the therapeutic period. BMP2 has been shown to act as a tumour suppressor, promoting apoptosis in colonic epithelial cells ${ }^{(41)}$. BMP2 expression was absent in the microadenomas of patients with familial adenomatous polyposis $^{(41)}$. Furthermore, BMP2 has been shown to stimulate the production of $\mathrm{IL}-18^{(42)}$. Previously, we reported that oral administration of bLF increased the production of IL-18 in the intestinal epithelium, thereby increasing NK cell activity in mice ${ }^{(19)}$. It has also been reported that IL-11 signalling is essential for the differentiation of $\mathrm{NK}$ cells in certain organs $^{(43)}$. We propose that the immunomodulatory activity of bLF, particularly the enhancement of NK cell activity, is associated with these factors.

In conclusion, oral administration of bLF protected against inflammation in mice with hepatitis. Orally ingested bLF enhanced the expression of IL-11 and BMP2 in the small intestine. In IL-11R $\alpha$-null mice, the anti-inflammatory and BMP2-inducing activities of orally administered bLF were abolished. The anti-inflammatory effect of orally administered bLF may arise from its promotion of IL-11 production in the small intestine.

\section{Acknowledgements}

The authors thank Mr Hirokazu Hamano for assistance with the statistical analysis.

The present study received no specific grant from any funding agency from commercial or not-for-profit sectors.

The authors' contributions are as follows: T. K. designed and conducted the study, analysed the data and wrote the manuscript; A. T. conducted the research and analysed the data; K. Y. and K. I. revised the manuscript; T. K. had primary responsibility for the final content. All the authors read and approved the final manuscript.

There are no conflicts of interest.

\section{References}

1. Togawa J, Nagase H, Tanaka K, et al. (2002) Lactoferrin reduces colitis in rats via modulation of the immune system and correction of cytokine imbalance. Am J Physiol Gastrointest Liver Physiol 283, G187-G195.

2. Tsubota A, Yoshikawa T, Nariai K, et al. (2008) Bovine lactoferrin potently inhibits liver mitochondrial 8-OHdG levels and retrieves hepatic OGG1 activities in Long-Evans Cinnamon rats. J Hepatol 48, 486-493.

3. Ushida Y, Sekine K, Kuhara T, et al. (1999) Possible chemopreventive effects of bovine lactoferrin on esophagus and lung carcinogenesis in the rat. Jpn J Cancer Res 90, 262-267.

4. Kuhara T, Iigo M, Itoh T, et al. (2000) Orally administered lactoferrin exerts an antimetastatic effect and enhances production of IL-18 in the intestinal epithelium. Nutr Cancer 38 , 192-199.

5. Horiuchi Y, Higuchi T, Tatsumi K, et al. (2009) Lactoferrin is associated with a decrease in oocyte depletion in mice receiving cyclophosphamide. Fertil Steril 91, 2069-2078.

6. Guo HY, Jiang L, Ibrahim SA, et al. (2009) Orally administered lactoferrin preserves bone mass and microarchitecture in ovariectomized rats. J Nutr 139, 958-964.

7. Kozu T, Iinuma G, Ohashi Y, et al. (2009) Effect of orally administered bovine lactoferrin on the growth of adenomatous colorectal polyps in a randomized, placebo-controlled clinical trial. Cancer Prev Res 2, 975-983.

8. Tanaka K, Ikeda M, Nozaki A, et al. (1999) Lactoferrin inhibits hepatitis $\mathrm{C}$ virus viremia in patients with chronic hepatitis C: a pilot study. Jpn J Cancer Res 90, 367-371.

9. Manzoni P, Rinaldi M, Cattani S, et al. (2009) Bovine lactoferrin supplementation for prevention of late-onset sepsis in very low-birth-weight neonates: a randomized trial. JAMA 302, 1421-1428.

10. Ye XY, Wang HX, Liu F, et al. (2000) Ribonuclease, cell-free translation-inhibitory and superoxide radical scavenging activities of the iron-binding protein lactoferrin from bovine milk. Int J Biochem Cell Biol 32, 235-241.

11. Inubushi T, Kawazoe A, Miyauchi M, et al. (2012) Molecular mechanisms of the inhibitory effects of bovine lactoferrin on lipopolysaccharide-mediated osteoclastogenesis. J Biol Chem 287, 23527-23536.

12. Nozaki A, Ikeda M, Naganuma A, et al. (2003) Identification of a lactoferrin-derived peptide possessing binding activity to hepatitis C virus E2 envelope protein. J Biol Chem $\mathbf{2 7 8}$, 10162-10173.

13. Sferi RM, Dubany M, Boyaka PN, et al. (2004) The mode of oral bovine lactoferrin administration influences mucosal and systemic immune responses in mice. J Nutr $\mathbf{1 3 4}$ 403-409. 
14. Yin H, Cheng L, Holt M, et al. (2010) Lactoferrin protects against acetaminophen-induced liver injury in mice. Hepatology 51, 1007-1016.

15. Lehmann V, Freudenberg MA \& Galanos C (1987) Lethal toxicity of lipopolysaccharide and tumor necrosis factor in normal and D-galactosamine-treated mice. J Exp Med 165, $657-663$

16. Nakatsuka R, Taniguchi M, Hirata M, et al. (2007) Transient expression of bone morphogenic protein-2 in acute liver injury by carbon tetrachloride. J Biochem 141, 113-119.

17. Yamaguchi M, Matsuura M, Kobayashi K, et al. (2001) Lactoferrin protects against development of hepatitis caused by sensitization of Kupffer cells by lipopolysaccharide. Clin Diagn Lab Immunol 8, 1234-1239.

18. Kuwata H, Yamauchi K, Teraguchi S, et al. (2001) Functional fragments of ingested lactoferrin are resistant to proteolytic degradation in the gastrointestinal tract of adult rats. $J$ Nutr 131, 2121-2127.

19. Kuhara T, Yamauchi K, Tamura Y, et al. (2006) Oral administration of lactoferrin increases NK cell activity in mice via increased production of IL-18 and type I IFN in the small intestine. J Interf Cytok Res 26, 489-499.

20. Kuhara T, Yamauchi K \& Iwatsuki K (2012) Bovine lactoferrin induces interleukin-11 production in a hepatitis mouse model and human intestinal myofibroblasts. Eur J Nutr $\mathbf{5 1}$ 343-351.

21. Du X \& Williams DA (1997) Interleukin-11: review of molecular, cell biology, and clinical use. Blood 89, 3897-3908.

22. Kawakami T, Takahashi T, Shimizu H, et al. (2006) Highly liver-specific heme oxygenase- 1 induction by interleukin- 11 prevents carbon tetrachloride-induced hepatotoxicity. Int $J$ Mol Med 18, 537-546.

23. Trepicchio WL, Wang L, Bozza M, et al. (1997) IL-11 regulates macrophage effector function through the inhibition of nuclear factor-кB. J Immunol 159, 5661-5670.

24. Sims NA, Jenkins BJ, Nakamura A, et al. (2005) Interleukin-11 receptor signaling is required for normal bone remodeling. J Bone Miner Res 20, 1093-1102.

25. Bao L, Devi S, Bowen-Shauver J, et al. (2006) The role of interleukin-11 in pregnancy involves up-regulation of $\alpha 2$-macroglobulin gene through Janus kinase 2-signaling transducer and activator of transcription 3 pathway in the deciduas. Mol Endocrinol 20, 3240-3250.

26. Nandurkar HH, Robb L, Tarlinton D, et al. (1997) Adult mice with targeted mutation of the interleukin-11 receptor (IL11Ra) display normal hematopoiesis. Blood 90, 2148-2159.

27. Jonker AM, Dijkhuis FW, Hardonk MJ, et al. (1994) Immunohistochemical study of hepatic fibrosis induced in rats by multiple galactosamine injections. Hepatology 19, 775-781.

28. Iwasa M, Kaito M, Ikoma J, et al. (2002) Lactoferrin inhibits hepatitis $\mathrm{C}$ virus viremia in chronic hepatitis $\mathrm{C}$ patients with high viral loads and HCV genotype 1b. Am J Gastroenterol 97, 766-767.
29. Ueno H, Sato T, Yamamoto S, et al. (2006) Randomized, double-blind, placebo-controlled trial of bovine lactoferrin in patients with chronic hepatitis C. Cancer Sci 97, 1105-1110.

30. Konishi M, Iwasa M, Yamauchi K, et al. (2006) Lactoferrin inhibits lipid peroxidation in patients with chronic hepatitis C. Hepatol Res 36, 27-32.

31. Qui BS, Pfeiffer CJ \& Keith JC Jr (1996) Protection by recombinant human interleukin-11 against experimental TNBinduced colitis in rats. Dig Dis Sci 41, 1625-1630.

32. Bozza M, Bliss JL, Maylor R, et al. (1999) Interleukin-11 reduces T-cell-dependent experimental liver injury in mice. Hepatology 30, 1441-1447.

33. Ellis M, Zwaan F, Hedstrom U, et al. (2003) Recombinant human interleukin 11 and bacterial infection in patients with haematological malignant disease undergoing chemotherapy: a double-blind placebo-controlled randomized trial. Lancet 361, 275-280.

34. Trepicchio WL, Ozawa M, Walters IB, et al. (1999) Interleukin-11 therapy selectively downregulates type I cytokine proinflammatory pathways in psoriasis lesions. J Clin Invest 104, 1527-1537.

35. Yamauchi K, Hiruma M, Yamazaki N, et al. (2000) Oral administration of bovine lactoferrin for treatment of tinea pedis. A placebo-controlled, double-blind study. Mycoses 43, 197-202.

36. Lawitz EJ, Hepburn MJ \& Casey TJ (2004) A pilot study of interleukin-11 in subjects with chronic hepatitis $C$ and advanced liver disease nonresponsive to antiviral therapy. Am J Gastroenterol 99, 2359-2364.

37. Babitt JL, Huang FW, Xia Y, et al. (2007) Modulation of bone morphogenetic protein signaling in vivo regulates systemic iron balance. J Clin Invest 117, 1933-1939.

38. Chen D, Zhao M \& Mundy GR (2004) Bone morphogenetic proteins. Growth Factors 22, 233-241.

39. Takeuchi $Y$, Watanabe $S$, Ishii G, et al. (2002) Interleukin-11 as a stimulatory factor for bone formation prevents bone loss with advancing age in mice. J Biol Chem 277, 49011-49018.

40. Nakashima K, Yanagisawa M, Arakawa H, et al. (1999) Synergistic signaling in fetal brain by stat3-smad1 complex bridged by p300. Science 284, 479-482.

41. Hardwick JC, Van Den Brink GR, Bleuming SA, et al. (2004) Bone morphogenetic protein 2 is expressed by, and acts upon, mature epithelial cells in the colon. Gastroenterology 126, 111-121.

42. Hori M, Sawai H, Tsuji Y, et al. (2006) Bone morphogenetic protein-2 counterregulates interleukin-18 mRNA and protein in MC3T3-E1 mouse osteoblastic cells. Connect Tissue Res 47, 124-132.

43. Ain R, Trinh ML \& Soares MJ (2004) Interleukin-11 signaling is required for the differentiation of natural killer cells at the maternal-fetal interface. Dev Dyn 231, 700-708. 